Article

\title{
Laminar Flame Characteristics of C1-C5 Primary Alcohol-Isooctane Blends at Elevated Temperature
}

\author{
Qianqian Li *, Wu Jin and Zuohua Huang * \\ State Key Laboratory of Multiphase Flow in Power Engineering, Xi'an Jiaotong University, Xi'an 710049, China; \\ jinwu_xian@163.com \\ * Correspondence: qianqianli@mail.xjtu.edu.cn (Q.L.); zhhuang@mail.xjtu.edu.cn (Z.H.); \\ Tel.: +86-29-8266-5075 (Q.L. \& Z.H.)
}

Academic Editor: Enrico Sciubba

Received: 23 April 2016; Accepted: 24 June 2016; Published: 30 June 2016

\begin{abstract}
The laminar combustion characteristics of blends of isooctane and C1-C5 primary alcohols (i.e., methanol, ethanol, $n$-propanol, $n$-butanol and $n$-pentanol) were investigated using the spherical expanding flame methodology in a constant volume chamber at various equivalence ratios and volume fractions of alcohol. The stretch effect was removed using the nonlinear methodology. The results indicate that the laminar flame speeds of alcohol-isooctane blends increase monotonously with the increasing volume fraction of alcohol. Among the five alcohols, the addition of methanol is identified to be the most effective in enhancing laminar flame speed. The addition of ethanol results in an approximately equivalent laminar flame speed enhancement rate as those of $n$-propanol, $n$-butanol and n-pentanol at ratios of 0.8 and 1.5, and a higher rate at 1.0 and 1.2. An empirical correlation is provided to describe the laminar flame speed variation with the volume fraction of alcohol. Meanwhile, the laminar flame speed increases with the mass content of oxygen in the fuel blends. At the equivalence ratio of 0.8 and fixed oxygen content, similar laminar flame speeds are observed with different alcohols blended into isooctane. Nevertheless, with the increase of equivalence ratio, heavier alcohol-isooctane blends tend to exhibit higher values. Markstein lengths of alcohol-isooctane blends decrease with the addition of alcohol into isooctane at 0.8, 1.0 and 1.2, however they increase at 1.5. This is consistent with the behavior deduced from the Schlieren images.
\end{abstract}

Keywords: primary alcohol; isooctane; laminar flame speed; oxygen content; Markstein length; empirical correlation

\section{Introduction}

Driven by energy shortages and environmental issues, there has been great interest in the development of alternative fuels in recent years. Alcohols, considered a renewable resource, are being extensively investigated in all fields. Unlike traditional fuels, alcohols contain oxygen, which is beneficial for complete combustion and the reduction of toxic emissions [1-8]. Specifically, light alcohols, e.g., methanol and ethanol, have been successfully utilized as octane boosters for traditional fuels. Heavy alcohols have high energy contents and blend well with traditional fuels. Isooctane is identified as the representative branched paraffin and, hence an important constituent in the surrogates of traditional fuels [9-11], therefore, investigating alcohol-isooctane blends can provide valuable information for understanding the potential of alcohols as alternative fuels.

Laminar flame characteristics, namely laminar flame speed and flame instability properties, are the fundamental physico-chemical information in evaluating the flame propagation process and turbulent flame research. In addition, laminar flame speed is widely adopted to validate chemical kinetics models. The laminar combustion characteristics of pure isooctane flames have been extensively investigated under various initial conditions in the past years [12-18]. Recently, studies on the laminar 
flames of alcohols have received increasing attention. Saeed and Stone [19] and Zhang et al. [20] studied the laminar flames of methanol in a constant volume chamber with laminar flame speeds at different determined initial temperatures and pressures. Togbé et al. [21] presented a set of laminar flame speeds of $n$-pentanol at $0.1 \mathrm{MPa}, 423 \mathrm{~K}$ to evaluate the accuracy of the $n$-pentanol model. Veloo et al. [22,23] measured the laminar flame speeds of methanol, ethanol, $n$-propanol and $n$-butanol flames in a counterflow configuration. Their results showed that methanol presents similar flame speeds as the other alcohols for lean mixtures, but yields significantly higher values for rich mixtures. This result was consistent with the conclusions of Beeckmann et al. [24] in a subsequent study on C1-C4 primary alcohols at elevated pressure. Sarathy et al. [25] reviewed the recent developments in alcohol combustion studies, and laminar flame speeds of different alcohols found in the literature were provided [25]. In addition, a comprehensive model covering C1-C5 alcohols was developed and adopted to simulate the laminar flame speeds at $353 \mathrm{~K}$. The simulation results indicated that methanol exhibits the highest laminar flame speed, followed by ethanol and C3-C5 primary alcohols. Zhang et al. [26,27] determined the laminar flame speeds and Markstein lengths of $n$-butanol-isooctane blends at elevated temperatures with a spherical propagating flame. They also investigated the cellular instability characteristics by analyzing the critical Peclect numbers calculated from the Schlieren pictures and stability theory. Broustail et al. $[28,29]$ experimentally evaluated the laminar flame speeds and Markstein lengths of $n$-butanol-isooctane and ethanol-isooctane blends at different initial temperatures and pressures in a constant volume chamber. An empirical formula was given to relate the laminar flame speed and the volume fraction of alcohol. Gulder et al. [30] studied the laminar flame speeds of methanol-isooctane blends at different determined blending ratios. Their results indicated that the laminar flame speed decreased with the addition of methanol to isooctane. Since there is no accurate model for methanol-isooctane blend combustion, it was speculated that the reason was that the methanol product formaldehyde may consume the intermediate radicals and suppress the oxidation reactivity. Subsequently, Gülder et al. [31] studied the effects of blending ethanol into isooctane on the laminar flame speed, and found the isooctane combustion was strongly promoted by the addition of ethanol. In general, experimental research on alcohol-isooctane blends is still scarce and no comprehensive comparative study on the blending of different alcohols into isooctane has been performed.

As mentioned above, alcohols are different from traditional fuels due to the presence of oxygen in alcohols. Engine tests suggest that oxygen content in the alcohol fuel is relevant to the knocking resistance and the harmful emissions of $\mathrm{NO}_{x}$, soot and carbonyl [2,3,32]. Gautam et al. [2,3] investigated the combustion and emission characteristics of a single-cylinder engine fueled with $\mathrm{C} 1-\mathrm{C} 5$ alcohol-gasoline blends. It was concluded that with the increase of oxygen content in the fuel blends, knocking resistance is enhanced, but $\mathrm{NO}_{x}$ emissions are increased significantly at high compression ratios. Sathiyagnanam et al. [33] studied the emission characteristics of hexanol-ethanol-diesel blends in a diesel engine. The results indicated that soot emissions decrease significantly with increasing oxygen content. Farkade and Pathre [34] compared the effects of blending methanol, ethanol and $n$-butanol into gasoline on engine performance. Their results showed that $\mathrm{CO}$ and HC emissions decreased with the increase in oxygen content and the better engine performance is achieved with oxygen contents in the blends equaling $5 \%$. However, limited fundamental investigation has been carried out on the effect of oxygen content on laminar combustion characteristics.

In this study, the laminar flame speeds and Markstein lengths of C1-C5 primary alcohol-isooctane blends were acquired via a spherical propagating flame in a constant volume chamber. The data were determined at an initial temperature of $363 \mathrm{~K}$, initial pressure of $0.1 \mathrm{MPa}$, four equivalence ratios $(0.8$, $1.0,1.2,1.5)$ and different volume fractions of alcohol $(0 \%, 20 \%, 40 \%, 60 \%, 80 \%, 100 \%)$. Based on the data, the dependencies of the laminar flame speed and Markstein length on the volume fraction of alcohol were interpreted, and a correlation describing the dependence of the laminar flame speed on volume fraction of alcohol was provided. In addition, the effect of oxygen content on the variation of laminar flame speed was illustrated. 


\section{Experimental Apparatus and Data Derivation}

The experimental apparatus utilized to determine the laminar flame speed is composed of five parts: a cylinder chamber with an inner diameter of $180 \mathrm{~mm}$ and a length of $210 \mathrm{~mm}$, an ignition system, a high speed camera (Phantom V611, Vision Research Inc., Wayne, NJ, USA), the control system and the optical system. Two quartz windows mounted on the two sides of the chamber provide the optical path. The high temperature of $363 \mathrm{~K}$ was accomplished by heating the chamber with a $1500 \mathrm{~W}$ heating tape surrounding the chamber. The pressure and temperature were respectively monitored by a pressure transducer and a thermocouple arranged on the chamber. At the beginning of each experiment, the chamber was heated up to the target temperature and evacuated. The liquid fuel was injected into the chamber with a microliter syringe. At least $5 \mathrm{~min}$ was allowed to elapse to ensure the full evaporation of the liquid fuel. Then dry air composed of $21 \% \mathrm{O}_{2}(>99.95 \%)$ and $79 \% \mathrm{~N}_{2}(>99.95 \%)$ was introduced into the chamber. After waiting for at least $6 \mathrm{~min}$ to achieve uniform mixing, ignition was performed using the spark electrodes located in the center of the chamber. Meanwhile, the high speed camera was initiated to track the flame propagation. More details of the experimental setup and procedures can be found in previous studies [35-37]. The liquid fuels (C1-C5 primary alcohols and isooctane) involved in present study had purities over $99 \%$ and the specifications listed in Table 1. It is seen that the heating values of alcohols are lower than that of isooctane and heavier alcohols have higher heating values. Among the five alcohols, the oxygen content decreases monotonously with increasing length of the carbon chain.

Table 1. Specifications of the fuels involved in this study $[2,3,38]$.

\begin{tabular}{ccccccc}
\hline Property & Isooctane & Methanol & Ethanol & $n$-Propanol & $n$-Butanol & $n$-Pentanol \\
\hline Chemical formula & $\mathrm{C}_{8} \mathrm{H}_{18}$ & $\mathrm{CH}_{4} \mathrm{O}$ & $\mathrm{C}_{2} \mathrm{H}_{6} \mathrm{O}$ & $\mathrm{C}_{3} \mathrm{H}_{8} \mathrm{O}$ & $\mathrm{C}_{4} \mathrm{H}_{10} \mathrm{O}$ & $\mathrm{C}_{5} \mathrm{H}_{12} \mathrm{O}$ \\
Molecular weight $\left(\mathrm{g} \cdot \mathrm{mol}^{-1}\right)$ & 114.23 & 32.04 & 46.07 & 60.1 & 74.12 & 88.15 \\
Oxygen content $(\mathrm{wt} \%)$ & 0 & 49.93 & 34.73 & 26.62 & 21.59 & 18.15 \\
Density $\left(\mathrm{g} \cdot \mathrm{cm}^{-3}\right)$ & 691.9 & 792 & 789 & 804 & 810 & 811 \\
Boiling point $\left({ }^{\circ} \mathrm{C}\right)$ & 99.3 & 64.7 & 78.37 & 97 & 117.7 & $137-139$ \\
Vapor pressure at $20^{\circ} \mathrm{C}(\mathrm{kPa})$ & 5.5 & 13.02 & 5.95 & 1.99 & 0.82 & 0.2 \\
Flash point $\left({ }^{\circ} \mathrm{C}\right)$ & -12 & 11 & 13 & 22 & 35 & 49 \\
Lower heating value $\left(\mathrm{MJ} \cdot \mathrm{kg}^{-1}\right)$ & 44.4 & 19.58 & 26.83 & 30.63 & 33.09 & 34.65 \\
Solubility in water & Insoluble & Soluble & Soluble & Soluble & Slight soluble & Slight soluble \\
\hline
\end{tabular}

The flame radius, $r_{\mathrm{f}}$, can be directly acquired from the Schlieren pictures of flame propagation. The stretched flame propagation speed is therefore determined by:

$$
S_{\mathrm{b}}=\frac{\mathrm{d} r_{\mathrm{f}}(t)}{\mathrm{d} t}
$$

Both linear and nonlinear methodologies were developed to describe the relationship between the stretched flame propagation speed and the stretched rate. Here a nonlinear expression $[39,40]$ was adopted and is expressed as:

$$
S_{\mathrm{b}}=S_{\mathrm{b}}^{0}-S_{\mathrm{b}}^{0} L_{\mathrm{b}} \cdot 2 / r_{\mathrm{f}}
$$

where $S_{\mathrm{b}}^{0}$ and $L_{\mathrm{b}}$ represents the unstretched flame speed and Markstein length, respectively, and $2 / r_{\mathrm{f}}$ is linked to the stretch rate through the equation $\mathrm{k}=\left(2 / r_{\mathrm{f}}\right) \cdot S_{\mathrm{b}}$. Finally, the laminar flame speed is deduced on the basis of mass conservation by the expression:

$$
S_{\mathrm{u}}^{0}=\rho_{\mathrm{b}} S_{\mathrm{b}}^{0} / \rho_{\mathrm{u}}
$$

where $\rho_{\mathrm{b}}$ and $\rho_{\mathrm{u}}$ are the densities of the burned and unburned gas, respectively.

The spark ignition and the chamber confinement are recognized to affect the accuracy of laminar flame speed measurements, therefore a flame radius of $8-22 \mathrm{~mm}$ was utilized to do the data processing. The total experimental uncertainty was evaluated according to the theory of Moffat et al. [41] which has been widely adopted in previous studies [42-44]. It can be described as:

$$
\delta_{S_{\mathrm{u}}^{0}}=\sqrt{\left(B_{S_{\mathrm{u}}^{0}}\right)^{2}+\left(t_{1-\alpha / 2}(v) \sigma_{S_{\mathrm{u}}^{0}}\right)^{2}}
$$


where $t_{1-\alpha / 2}(v)$ is the Student's $t$ value at $95 \%$ confidence interval and the freedom degree of $v$; $\sigma_{S_{\mathrm{u}}^{0}}$ represents the standard deviation of $S_{\mathrm{u}}^{0} . B_{S_{\mathrm{u}}^{0}}$ is the total bias uncertainty of the determination methodology and can be obtained from the following equation:

$$
B_{S_{\mathrm{u}}^{0}}=\sqrt{\sum_{i=1}^{n}\left(\frac{\partial S_{\mathrm{u}}^{0}\left(x_{i}\right)}{\partial x_{i}} u_{i}\right)^{2}}
$$

where $x_{i}$ represents the factor influencing the measurement accuracy and $u_{i}$ is the deviation of $x_{i}$. Present total bias uncertainty was estimated to be $1.3-2 \mathrm{~cm} \cdot \mathrm{s}^{-1}$ with the detailed analysis given in $[44,45]$. The standard deviation $\left(\sigma_{S_{u}^{0}}\right)$ arising from data processing was $0.3-2 \mathrm{~cm} \cdot \mathrm{s}^{-1}$. At each condition, 40-80 pictures were utilized to do the data processing, thus the values of $v$ were 40-80. The total experimental uncertainty was finally determined with Equation (4) to be approximately $\pm 2-4 \mathrm{~cm} \cdot \mathrm{s}^{-1}$.

\section{Results and Discussion}

\subsection{Laminar Flame Speed}

Figure 1 shows the stretched flame propagation speed $\left(S_{\mathrm{b}}\right)$ of pure isooctane and alcohol flames versus stretch rate at $0.1 \mathrm{MPa}, 363 \mathrm{~K}$ and four different equivalence ratios. It is observed that isooctane flames always present the lowest $S_{\mathrm{b}}$ among all fuel flames, demonstrating that isooctane flames propagates the slowest. The difference between the alcohol flames changes with the variation of equivalence ratio. At $\varphi=0.8$ and 1.0, the methanol flame exhibits approximately the same $S_{\mathrm{b}}$ as the ethanol flame, and higher $S_{\mathrm{b}}$ values than those of the C3-C5 primary alcohol flames.
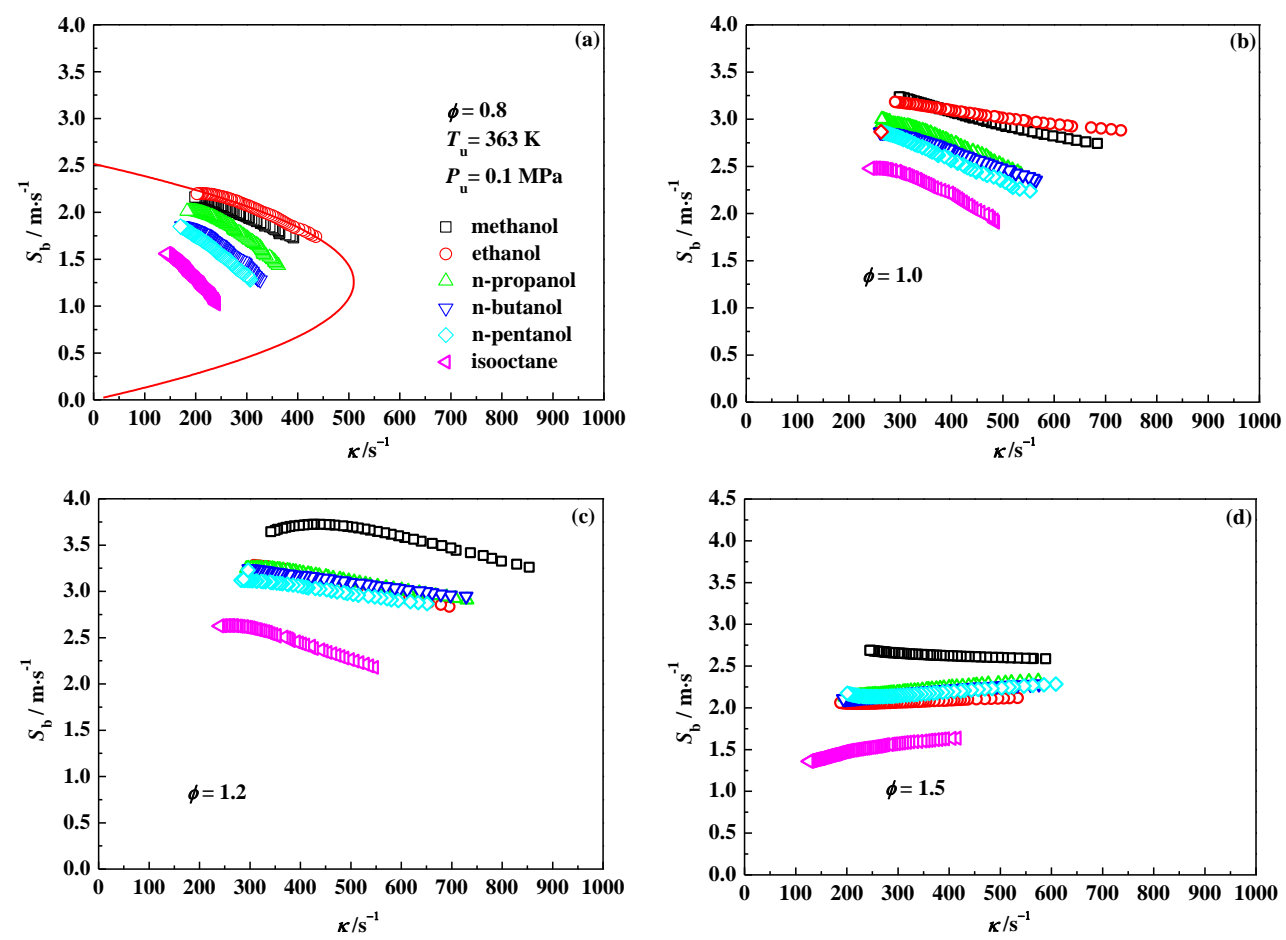

Figure 1. Stretched flame propagation speed vs. stretch rate at different equivalence ratios for pure isooctane and pure C1-C5 primary alcohol flames: (a) $\varphi=0.8$; (b) $\varphi=1.0$; (c) $\varphi=1.2$; and (d) $\varphi=1.5$. A line is shown in (a) to indicate the nonlinear extrapolation.

At $\varphi=1.2$ and $1.5, S_{\mathrm{b}}$ of methanol flame remains the fastest, while the $S_{\mathrm{b}}$ of the ethanol flame exhibits a similar value as the $\mathrm{C} 3-\mathrm{C} 5$ primary alcohols. At the four equivalence ratios, no significant difference is observed for the flame propagation speeds of the C3-C5 primary alcohols, although the $n$-propanol flame presents slightly higher values than that of $n$-butanol and $n$-pentanol at 0.8 . 
In Figure 2, laminar flame speeds measured in this study are compared with the data acquired from the literature to evaluate the performance of the experimental apparatus. Error bars are marked to indicate the experimental measurement uncertainty. Figure $2 a, b$ gives the laminar flame speeds of pure ethanol and isooctane flames at $0.1 \mathrm{MPa}$, respectively. It is seen the present data are in good agreement with the data from literatures [10,46-50]. Figure $2 c$ gives the laminar flame speeds of ethanol-isooctane blend-air mixtures versus volume fraction of ethanol at $0.1 \mathrm{MPa}$. It is seen the present data at $363 \mathrm{~K}$ is located between the two sets of data at $348 \mathrm{~K}$ and $373 \mathrm{~K}$ measured by Rau et al. [51]. This result is reasonable because of the fundamental effect of the initial temperature. To allow a direct comparison between the present data and the data of Rau et al. [51], an empirical relationship $S_{\mathrm{u}}^{0} \propto T_{\mathrm{u}}^{1.8}$ [52] was introduced to account for the effect of the $10 \mathrm{~K}$ temperature difference on the laminar flame speed. It is found that the $10 \mathrm{~K}$ difference results in a $1-2 \mathrm{~cm} / \mathrm{s}$ decrease in the laminar flame speed. The temperature adjusted data agree well with the present data. Figure $2 \mathrm{~d}$ shows the laminar flame speeds of $n$-butanol-isooctane blends at different equivalence ratios. The experiment conducted by Zhang et al. [27] was at $353 \mathrm{~K}$ which is $10 \mathrm{~K}$ lower than the present temperature, thus the data of Zhang et al. [27] were adjusted to match those at $363 \mathrm{~K}$. It is seen that the present data agree well with the data of Zhang et al. [27] at 0.8 equivalence ratio after temperature adjustment. At 1.0 and 1.5 , the data slightly deviate from the temperature-adjusted data but the deviations are within the experimental uncertainty.
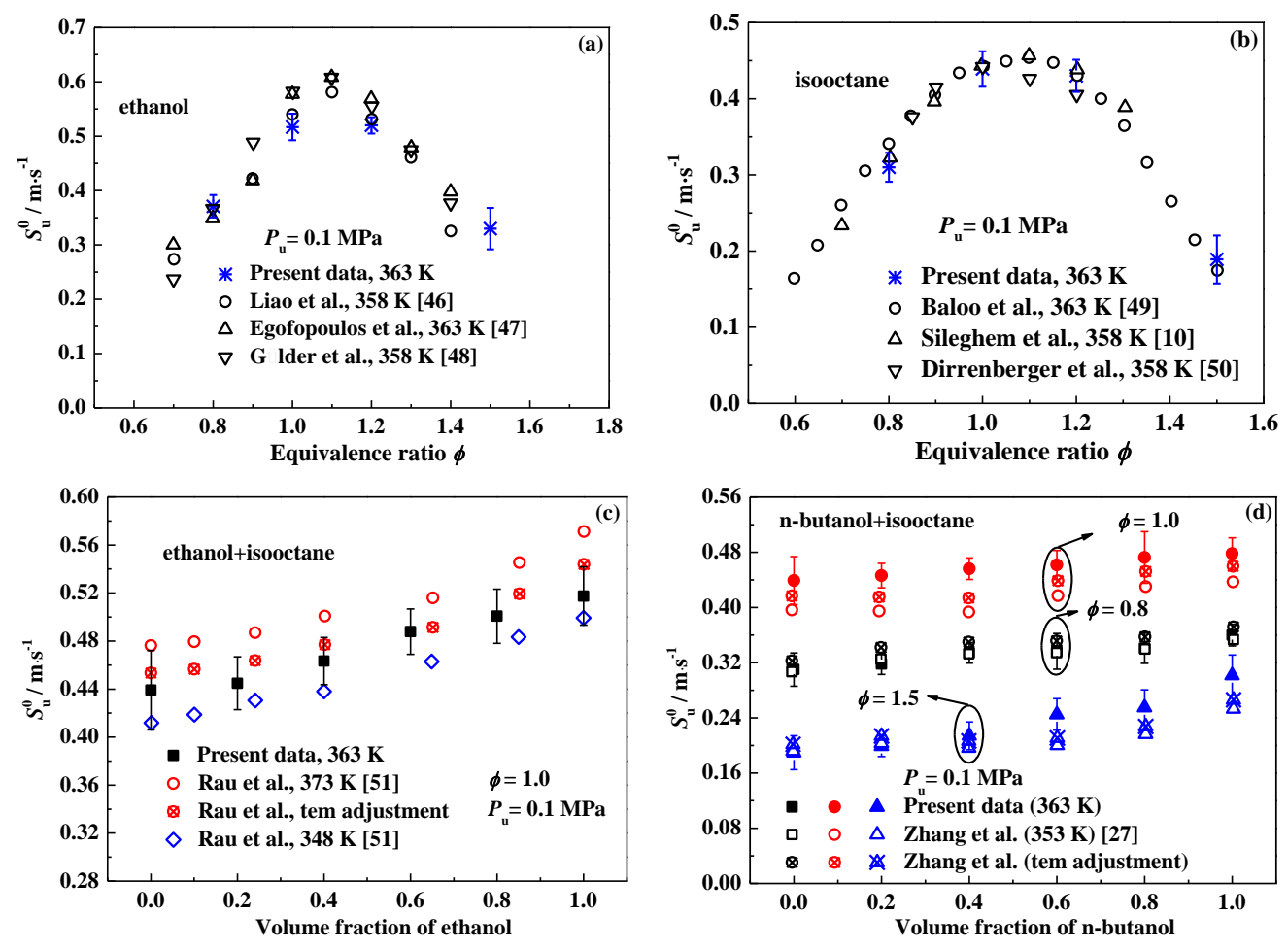

Figure 2. Laminar flame speeds of alcohol-isooctane blends acquired in present study and in literatures [10,27,46-51] at 0.1 MPa: (a) pure ethanol; (b) pure isooctane; (c) ethanol-isooctane blends; and (d) $n$-butanol-isooctane blends.

Figure 3 plots the laminar flame speeds of C1-C5 primary alcohol-isooctane blends at $363 \mathrm{~K}$, $0.1 \mathrm{MPa}$ and different equivalence ratios. Error bars are just indicated for methanol-isooctane blends for clarity. The laminar flame speeds exhibit a nonlinear increase with the addition of alcohol to isooctane. The increase rate depends on the kind of alcohol considered. This is consistent with the results obtained by Zhang et al. [27] and Broustail et al. [28,29]. It also provides support for the conclusions derived on engine tests that the combustion duration was decreased with the alcohols blended into gasoline. The methanol addition into isooctane is identified to be the most effective at promoting the flame propagation at different equivalence ratios. Therefore, a pure methanol flame gives the fastest flame 
speed among the different alcohol flames. The difference between methanol and the remaining alcohols is within $3 \mathrm{~cm} / \mathrm{s}$ at the equivalence ratio of 0.8 , but much greater at 1.0, 1.2 and 1.5. This result is consistent with the results obtained by Veloo et al. [22,23] and Beeckmann et al. [24] under rich mixture conditions. Under lean conditions, Veloo et al. [22] and Beeckmann et al. [24] found that methanol flame exhibits similar laminar flame speeds to ethanol, $n$-propanol and $n$-butanol flames, which is slightly different from the present result. In the present study, the addition of ethanol results in a similar laminar flame speed enhancement as those of $n$-propanol, $n$-butanol and $n$-pentanol at the equivalence ratios of 0.8 and 1.5, and a higher enhancement rate at 1.0 and 1.2. This result agrees well with the conclusions obtained by Broustail et al. [28,29] for ethanol-isooctane and $n$-butanol-isooctane blends.
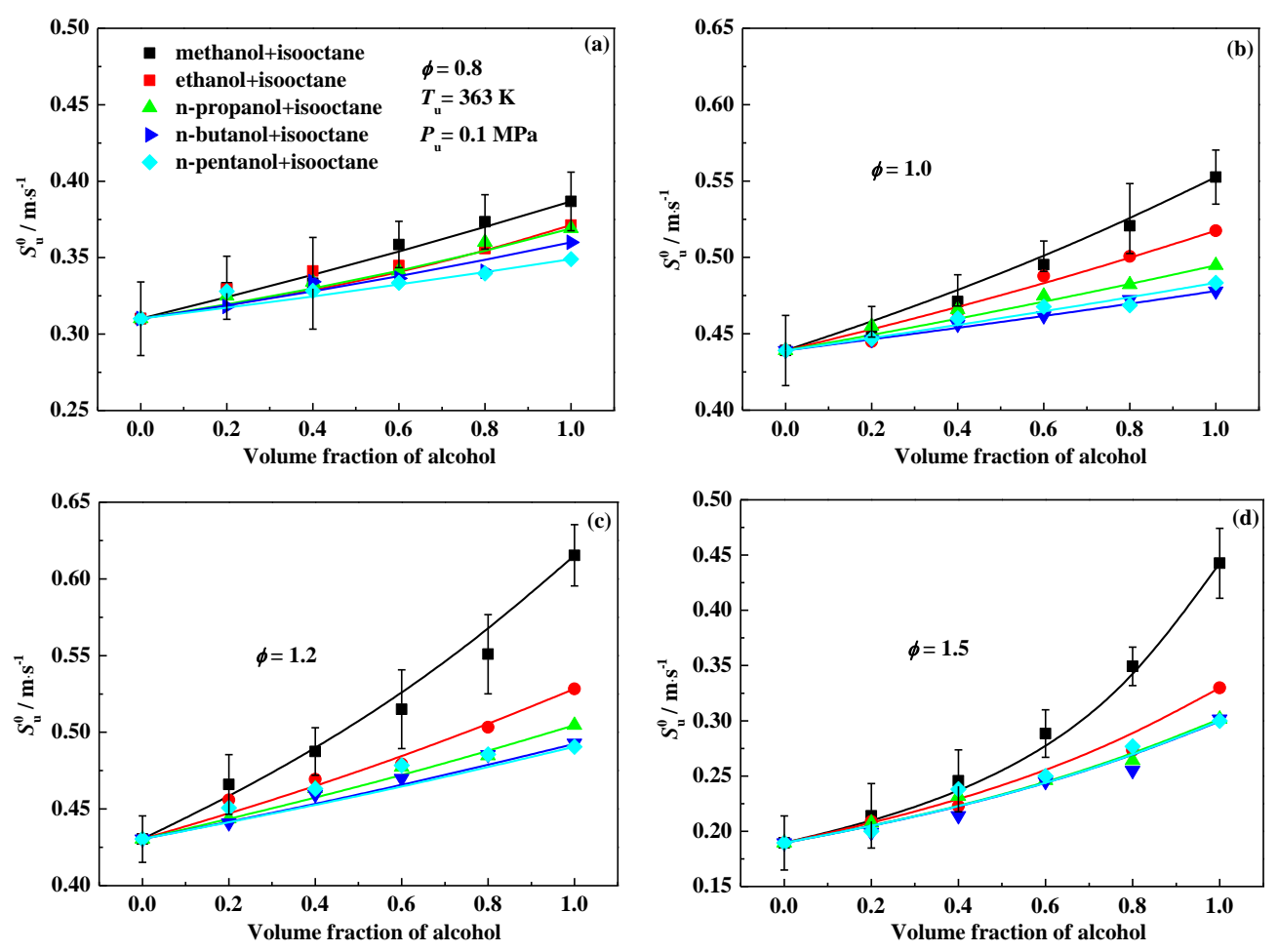

Figure 3. Laminar flame speeds of the alcohol-isooctane blends vs. volume fraction of alcohol at $363 \mathrm{~K}$, $0.1 \mathrm{MPa}$, and different equivalence ratios: (a) $\varphi=0.8$; (b) $\varphi=1.0$; (c) $\varphi=1.2$; and (d) $\varphi=1.5$. Lines are calculated using Equation (8) in Section 3.4.

\subsection{Interpretation on the Variation of Laminar Flame Speeds}

Laminar flame speed is closely linked to the properties of thermal, diffusive and chemical kinetics, which can be described as [53,54]:

$$
\rho_{\mathrm{u}} S_{\mathrm{u}}^{0} \propto\left(\lambda / C_{\mathrm{p}}\right) L e\left[\exp \left(-E_{\mathrm{a}} / R_{0} T_{\mathrm{ad}}\right)\right]
$$

where $L e, E a$ and $T_{\text {ad }}$ denotes the Lewis number, the activation energy and adiabatic temperature, respectively; and $\lambda / C_{\mathrm{p}}$ is the density-compensated thermal diffusivity. $T_{\mathrm{ad}}$ is calculated based on thermal equilibrium. Lewis number $(L e)$ is defined as the ratio of thermal and mass diffusivity and derived by:

$$
L e=\frac{\lambda}{\rho_{\mathrm{u}} C_{\mathrm{p}} D_{\mathrm{m}}}
$$

in which $\lambda$ is the thermal conductivity of the mixture, $C_{\mathrm{p}}$ is the specific heat of the mixture and $D_{\mathrm{m}}$ is the mass diffusivity of the deficient species. The Lennard-Jones potential data of the blends involved in the determination of $D_{\mathrm{m}}$ were calculated based on the mass average of the pure fuels. The terms of $T_{\mathrm{ad}}$ 
and $\left(\lambda / C_{\mathrm{p}}\right)$ Le represent the effects of the thermal and diffusive properties, respectively. Figure 4 shows $T_{\mathrm{ad}}$ of alcohol-isooctane blends at the equivalence ratio of 1.2, $363 \mathrm{~K}$ and $0.1 \mathrm{MPa}$. It is observed that $T_{\mathrm{ad}}$ decreases monotonously with the addition of alcohols, which is caused by the smaller heating values of $\mathrm{C} 1-\mathrm{C} 5$ alcohols compared to isooctane. Lower alcohols have smaller heating values referring to Table 1, thus leading to lower $T_{\mathrm{ad}}$ of their blends with isooctane for a fixed volume fraction of alcohol.

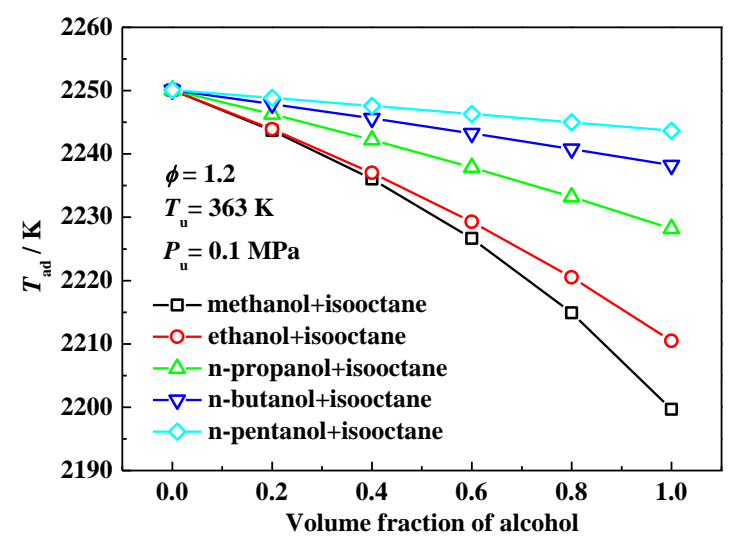

Figure 4. Adiabatic temperature of alcohol-isooctane blends vs. volume fraction of alcohol at $363 \mathrm{~K}$, $0.1 \mathrm{MPa}$ and the equivalence ratio of 1.2.

Figures 5 and 6 show the density compensated thermal diffusivity $\left(\lambda / C_{p}\right)$ and Lewis number (Le) of five alcohol-isooctane blends at $363 \mathrm{~K}, 0.1 \mathrm{MPa}$, respectively. $\lambda / C_{\mathrm{p}}$ and Le decrease with the increasing blending ratio of alcohol, and the values decrease more for lower alcohols. Therefore, methanol-isooctane blends have the lowest values of $\lambda / C_{\mathrm{p}}$ and Le for a fixed volume fraction of alcohol. This demonstrates that methanol is more diffusive than the other primary alcohols and isooctane. Combining with the result of $T_{\mathrm{ad}}$, it is concluded that both thermal and diffusive factors exert negative effects on laminar flame speed with the increasing volume fraction of alcohol. Moreover, such a negative effect is identified to be the strongest for the methanol-isooctane blends which, however, have the highest laminar flame speed. Therefore, it is speculated that the chemical kinetic effect is primarily responsible for the laminar flame speed variation with the addition of alcohols.

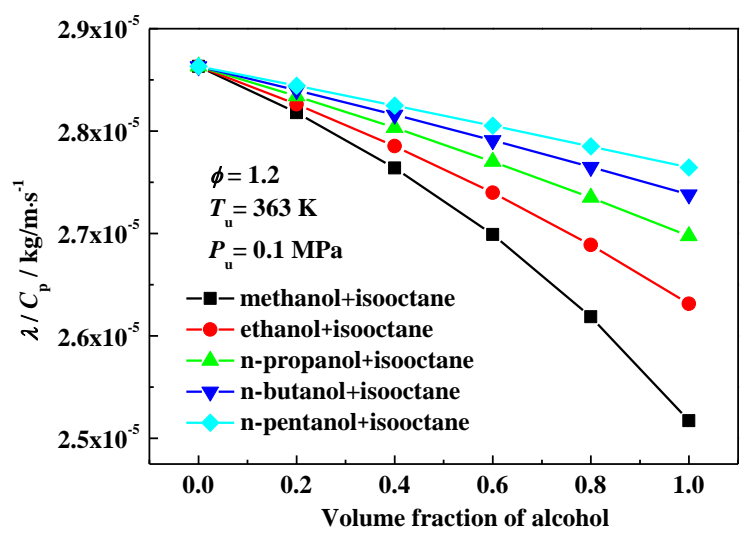

Figure 5. Density-compensated thermal diffusivity of alcohol-isooctane blend-air mixtures at $363 \mathrm{~K}$, $0.1 \mathrm{MPa}$ and the equivalence ratio of 1.2.

The laminar flame speed differences between the five alcohol-isooctane blends are inherently caused by the distinct combustion chemistries of the pure fuels. Therefore, the chemical kinetics of pure alcohols and isooctane were comparatively investigated. Figure 7 shows the simulations of $\mathrm{C} 1-\mathrm{C} 5$ primary alcohols and isooctane versus equivalence ratio at $363 \mathrm{~K}$ and $0.1 \mathrm{MPa}$. The simulations were 
carried out with the PREMIX code [55] coupling with CHEMKIN package [55-58]. In the simulations, the Soret effect as well as the mixture-averaged transport were used. Here we adopted the mechanism of C1-C5 alcohol combustion developed by Sarathy et al. [25] to simulate the alcohols' flames and the PRF mechanism proposed by Chaos et al. [59] to simulate the isooctane flames. It is seen that under lean conditions, the methanol simulation curves are slightly lower than those of ethanol, similar to those of the C3-C5 primary alcohols and higher than those of isooctane. Under rich conditions, the simulated methanol curves are the highest, followed by ethanol, $n$-propanol, $n$-butanol and $n$-pentanol, and isooctane flame gives the lowest values. This result accurately captures the differences between the pure fuels observed in the experimental data.
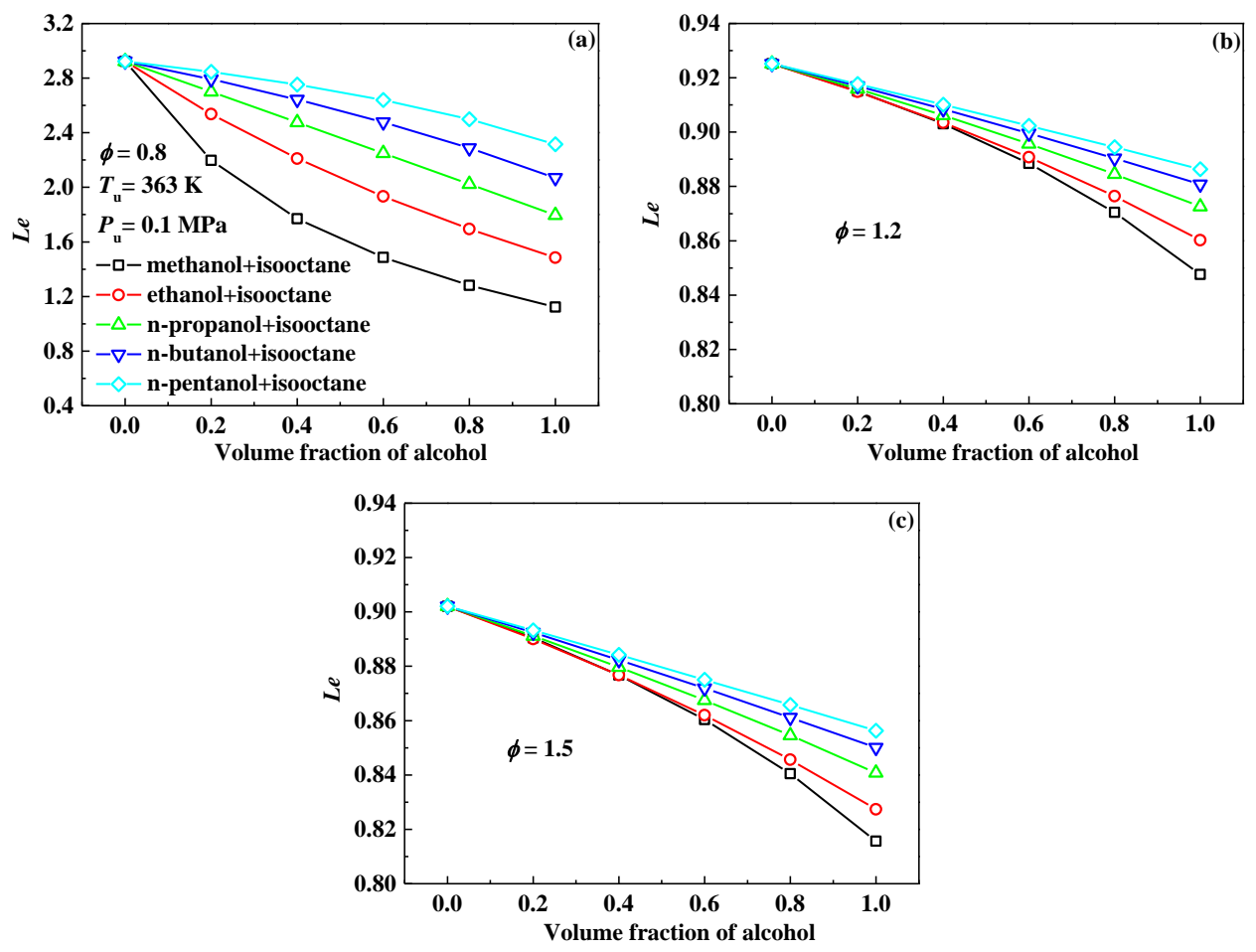

Figure 6. Lewis number of $\mathrm{C} 1-\mathrm{C} 5$ primary alcohol-isooctane blends at different equivalence ratios: (a) $\varphi=0.8$; (b) $\varphi=1.0$; and (c) $\varphi=1.2$.

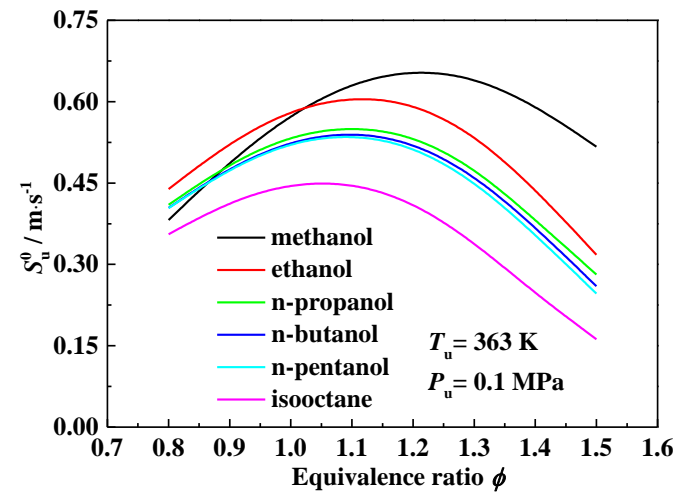

Figure 7. Simulations of C1-C5 primary alcohols and isooctane at $363 \mathrm{~K}$ and $0.1 \mathrm{MPa}$ using the mechanisms proposed by Sarathy et al. [25] and Chaos et al. [59], respectively.

Sensitivity analysis was performed to identify the key species and reactions highly sensitive to the laminar flame speed variation. The sensitivity coefficient, $S F_{i}$, is evaluated by the expression $S F_{i}=\frac{k_{i}}{S_{\mathrm{u}}^{0}} \frac{\partial S_{\mathrm{u}}^{0}}{\partial k_{i}}$, where $k_{i}$ represents the rate constant of reaction $i$. Figure 8 depicts the sensitivity 
coefficients of the laminar flame speeds of the pure alcohols and isooctane at $363 \mathrm{~K}, 0.1 \mathrm{MPa}$ and the equivalence ratio of 1.2. It is seen that the laminar flame speeds of different fuels are primarily sensitive to the kinetics of $\mathrm{H}_{2}$ and small hydrocarbons. Fuel-specific reactions are not included, suggesting they are not the rate-limiting reactions. This result is consistent with the observations on many other hydrocarbons $[14,45,52]$. Nevertheless, it is noted that the laminar flame speeds of heavier hydrocarbons (the heavier alcohols and isooctane) are more sensitive to the kinetics of stable species like $\mathrm{C}_{2} \mathrm{H}_{2}, \mathrm{C}_{3} \mathrm{H}_{6}$ and $i \mathrm{C}_{4} \mathrm{H}_{8}$. This indicates that the effects of the distributions of stable species on laminar flame speed are fairly significant for heavy alcohols and isooctane. The distributions of these key species revealed in the sensitivity analyses will change as different alcohols are blended into isooctane, and finally result in the variation of laminar flame speed.

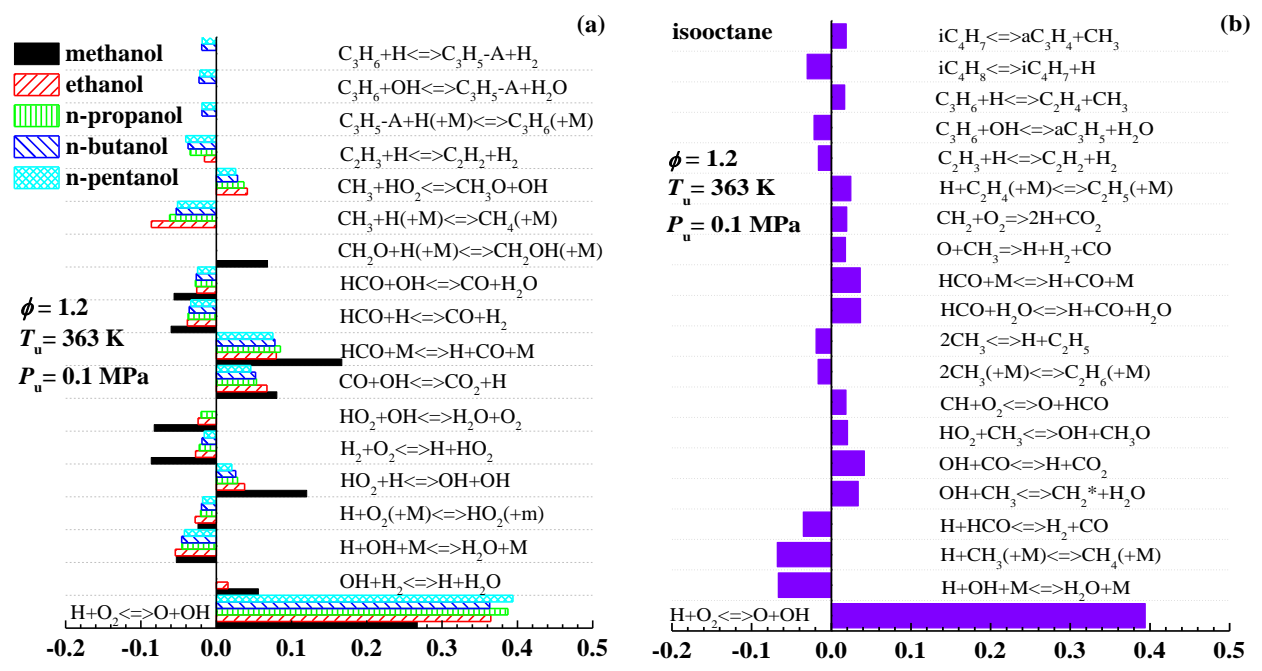

Figure 8. Normalized rate constant sensitivity coefficients on laminar flame speed for (a) pure C1-C5 primary alcohols and (b) pure isooctane at $363 \mathrm{~K}, 0.1 \mathrm{MPa}$ and the equivalence ratio of 1.2.

Figure 9 plots the mole fractions of key species in different fuel flames at $363 \mathrm{~K}, 0.1 \mathrm{MPa}$ and the equivalence ratio of 1.2. The concentrations of $\mathrm{H}$ and $\mathrm{OH}$ are positively relevant to the laminar flame speed. Obviously, the mole fractions of $\mathrm{H}, \mathrm{OH}$ in alcohol flames are significantly higher than those in isooctane flame, which explains why alcohols exhibit higher laminar flame speeds than isooctane. With the addition of alcohols into isooctane, the mole fractions of $\mathrm{O}$ and $\mathrm{OH}$ are increased, promoting the overall reactivity and enhancing the flame propagation. The mole fractions of $\mathrm{H}$ and $\mathrm{OH}$ in $\mathrm{C} 3-\mathrm{C} 5$ primary alcohol flames are similar, and lower than those in methanol and ethanol flames, which is consistent with the laminar flame speed conclusion. Figure 9c shows the mole fractions of $\mathrm{CH}_{3}$ in different fuel flames. It is observed that isooctane flame has the highest $\mathrm{CH}_{3}$ concentration, followed by $\mathrm{C} 2-\mathrm{C} 5$ primary alcohols and methanol flames. $\mathrm{CH}_{3}$ can be mainly consumed through two terminating reactions, $\mathrm{CH}_{3}+\mathrm{H}(+\mathrm{M})<=>\mathrm{CH}_{4}(+\mathrm{M})$ and $\mathrm{CH}_{3}+\mathrm{CH}_{3}$ $\Leftrightarrow=\mathrm{C}_{2} \mathrm{H}_{6}$. Therefore, a high concentration of $\mathrm{CH}_{3}$ will reduce the $\mathrm{H}$ and $\mathrm{CH}_{3}$ concentrations and inhibit the flame propagation. There is a much higher concentration of $\mathrm{CH}_{3}$ in ethanol flames than in methanol flames, contributing to the lower flame speed of ethanol than methanol. Figure $9 \mathrm{~d}$ shows the mole fractions of $\mathrm{C}_{3} \mathrm{H}_{6}$. The concentration of $\mathrm{C}_{3} \mathrm{H}_{6}$ increases as the alcohol becomes heavier, and isooctane flame has the highest $\mathrm{C}_{3} \mathrm{H}_{6}$ concentration. $\mathrm{C}_{3} \mathrm{H}_{6}$ are primarily consumed by $\mathrm{C}_{3} \mathrm{H}_{6}+\mathrm{H}<=>\mathrm{C}_{3} \mathrm{H}_{5}-\mathrm{A}+\mathrm{H}_{2}$ and $\mathrm{C}_{3} \mathrm{H}_{6}+\mathrm{OH}<=>\mathrm{C}_{3} \mathrm{H}_{5}-\mathrm{A}+\mathrm{H}_{2} \mathrm{O}$, as noted in Figure 8. Thus $a$ high concentration of $\mathrm{C}_{3} \mathrm{H}_{6}$ retards the overall reaction and the flame propagation. In summary, the species retarding the overall reactivity tends to exhibit higher concentrations in the flames of heavier alcohols and much higher in isooctane flames. With the additions of various alcohols into isooctane, the concentrations of the species are changed in different extent, finally causing the laminar flame speed distinctions. The kinetic analyses above provide strong support for our chemical kinetics considerations. 

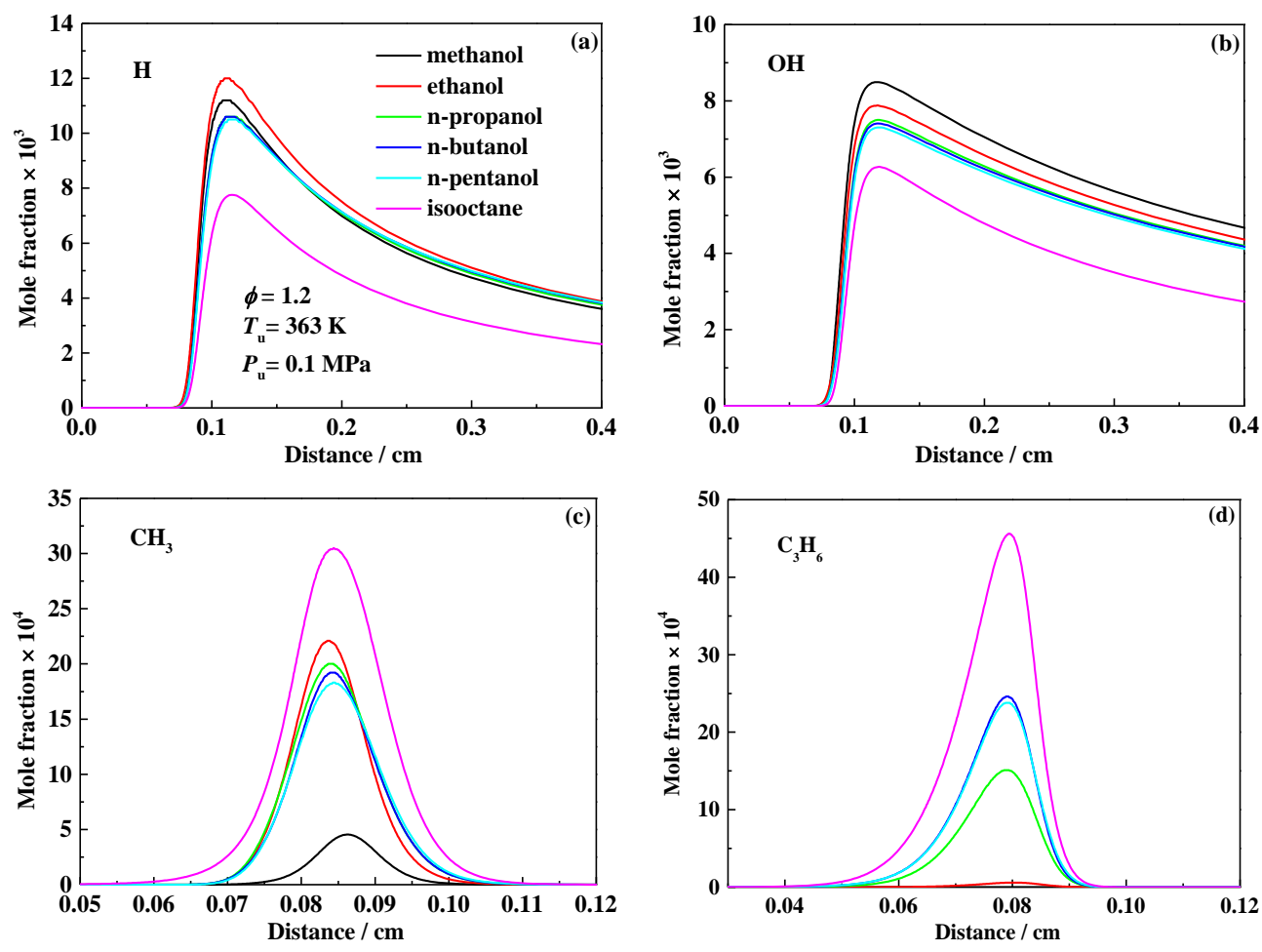

Figure 9. Mole fraction profiles of key species for pure isooctane and alcohol fuels at $363 \mathrm{~K}, 0.1 \mathrm{MPa}$ and equivalence ratio of 1.2: (a) $\mathrm{H}$; (b) $\mathrm{OH}$; (c) $\mathrm{CH}_{3}$; and (d) $\mathrm{C}_{3} \mathrm{H}_{6}$.

\subsection{The Effect of Oxygen Content}

To learn the effect of oxygen content on the laminar flame characteristics, the laminar flame speeds of the alcohol-isooctane blends were plotted in Figure 10 as a function of the mass content of oxygen in the blends at $363 \mathrm{~K}, 0.1 \mathrm{MPa}$ and four different equivalence ratios. At all equivalence ratios, with different alcohols added into isooctane, laminar flame speeds increase significantly with the increasing oxygen content. It confirms the conclusion reported by Gautam and Martin [2] that the combustion interval decreases with the increasing oxygen content in the fuel. At $\varphi=0.8$ and fixed oxygen content, laminar flame speeds are similar for the blends of isooctane and different alcohols. With the increase of equivalence ratio, deviations appear between different blends and tend to be greater. At a fixed oxygen content, the blends of isooctane and heavier alcohols exhibit faster flame speed, namely, methanol-isooctane blends have the slowest flame speed.

\subsection{Markstein Length and Flame Instability}

Markstein length, $L_{\mathrm{b}}$, extracted along with the unstretched flame propagation speed, characterizes the thermal-diffusive instability properties of the flame front and reflects the response of laminar flame speed to the stretch effect [54]. Positive values indicate a stable flame front while negative values indicate an unstable flame front. Figure 11a shows the Markstein length of $n$-propanol-isooctane blends versus volume fraction of $n$-propanol with the data listed in Table S1 in the Supplementary Materials. It is observed that $L_{\mathrm{b}}$ shows a decreasing trend at $\varphi=0.8,1.0$ and 1.2 with the addition of $n$-propanol into isooctane, demonstrating the thermal-diffusive instability is enhanced. At $\varphi=1.5$, $L_{\mathrm{b}}$ increases significantly, and the thermal-diffusive instability is suppressed. Similar behavior is also observed for the other alcohol-isooctane blends with the data provided in Tables S2-S5 in the Supplementary Materials. Figure $11 \mathrm{~b}$ plots $L_{\mathrm{b}}$ as the function of equivalence ratio for pure isooctane and C1-C5 primary alcohol flames at $363 \mathrm{~K}$ and $0.1 \mathrm{MPa}$ and the data can be found in Tables S1-S5 in the Supplementary Materials. Isooctane flame exhibits higher $L_{\mathrm{b}}$ than the alcohol flames under lean conditions while it yields lower values at extremely rich conditions. Therefore, crosses exist between 
the $L_{\mathrm{b}}-\varphi$ curve of isooctane and those of alcohols at the critical equivalence ratios $\left(\varphi^{*}\right)$. Specifically, at the equivalence ratio less than $\varphi^{*}, L_{\mathrm{b}}$ increases with the addition of alcohol into isooctane, and the thermal-diffusive instability is suppressed. At the equivalence ratio greater than $\varphi^{*}, L_{\mathrm{b}}$ decreases with the addition of alcohol, and the thermal-diffusive instability is enhanced. This behavior confirms the result reported by Zhang et al. [27] in their research of $n$-butanol-isooctane blends with the value of $\varphi^{*}$ identified to be 1.3. From Figure 11b, the values of $\varphi^{*}$ for the blends of isooctane and different alcohols are estimated to be 1.2-1.3 which are close to the result of Zhang et al. [27].
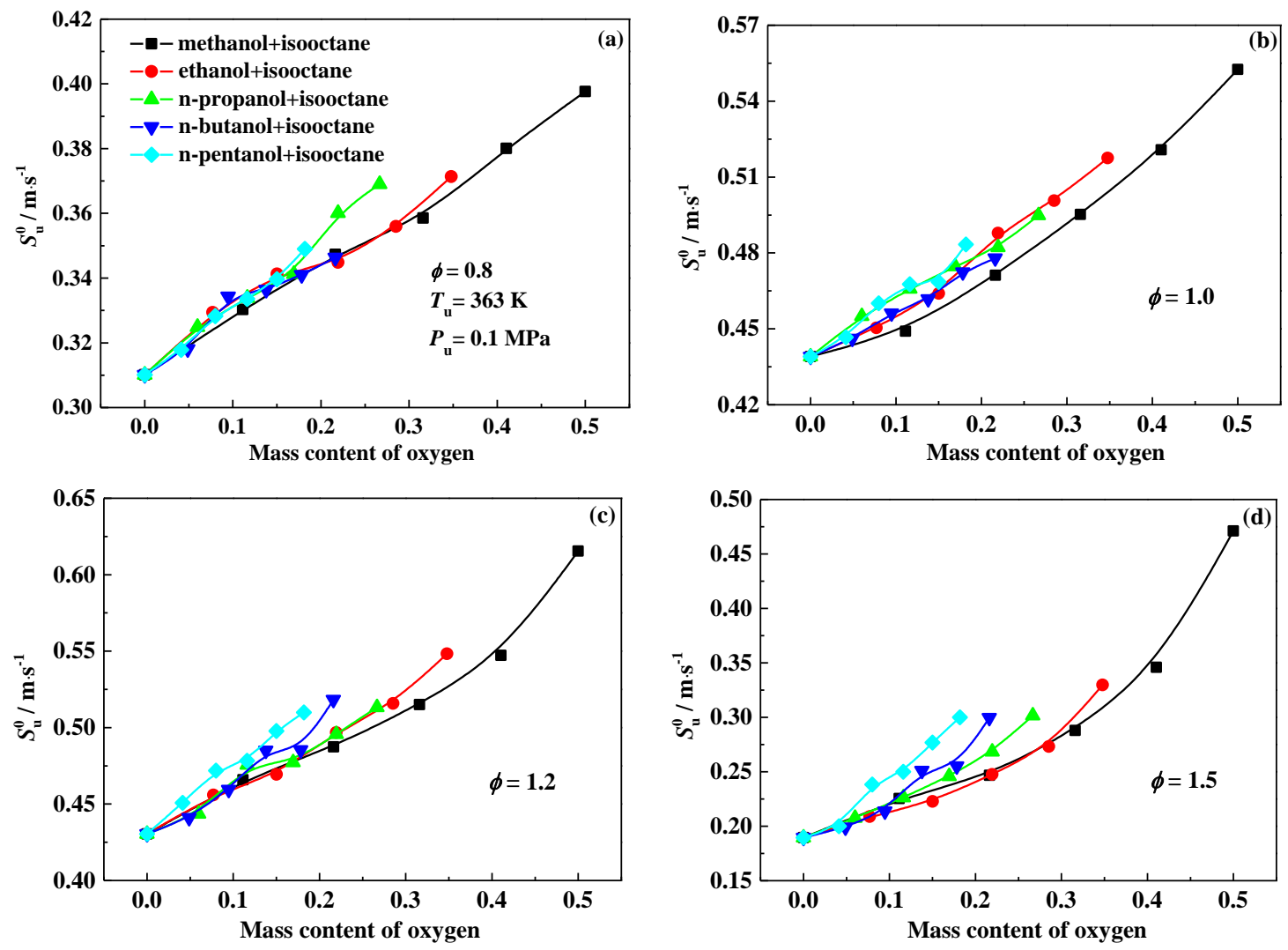

Figure 10. Laminar flame speeds of alcohol-isooctane blends vs. mass content of oxygen at $363 \mathrm{~K}$, $0.1 \mathrm{MPa}$, and different equivalence ratios: (a) $\varphi=0.8$; (b) $\varphi=1.0$; (c) $\varphi=1.2$; and (d) $\varphi=1.5$.
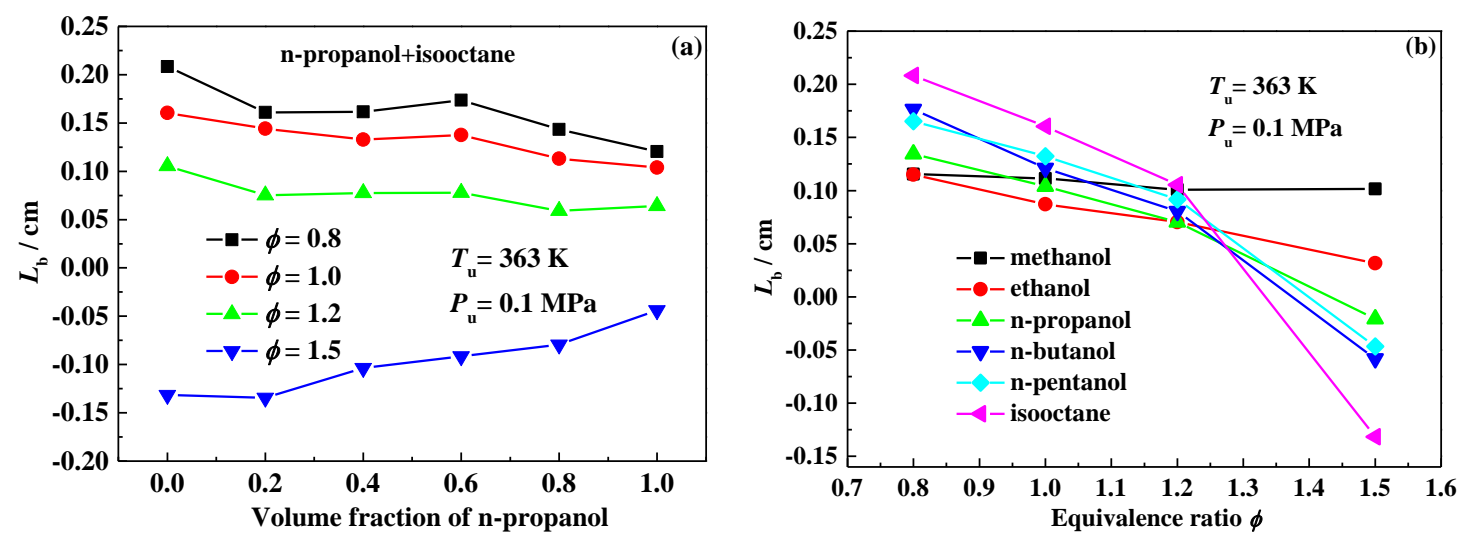

Figure 11. Markstein lengths of $n$-propanol-isooctane blends and pure fuels at $363 \mathrm{~K}, 0.1 \mathrm{MPa}$ : (a) $L_{\mathrm{b}}$ of $n$-propanol-isooctane blends; and (b) $L_{\mathrm{b}}$ of pure isooctane and alcohol flames. 
To better recognize the flame instability properties, the Schlieren images for the alcohol-isooctane blends at different blending ratios $\left(f_{\mathrm{v}, \mathrm{acl}}\right)$ and the equivalence ratio of 1.5 are shown in Figure 12 . For pure isooctane, cracks clearly appear on the flame front. With the increasing alcohol blending ratio, the number of cracks on the flame front displays a decreasing tendency. This demonstrates that the flame instability on the flame front is suppressed with the addition of alcohol. In particular, pure methanol and ethanol flames even present smooth flame fronts. Moreover, slight differences can be seen in that the methanol-isooctane blend with $80 \%$ methanol presents a smooth flame front, while there are cracks on the flame front of the ethanol-isooctane blend with $80 \%$ ethanol. Therefore, the addition of methanol is the most effective in suppressing the flame instability. This result is consistent with the Markstein length behavior observed in Figure 11.
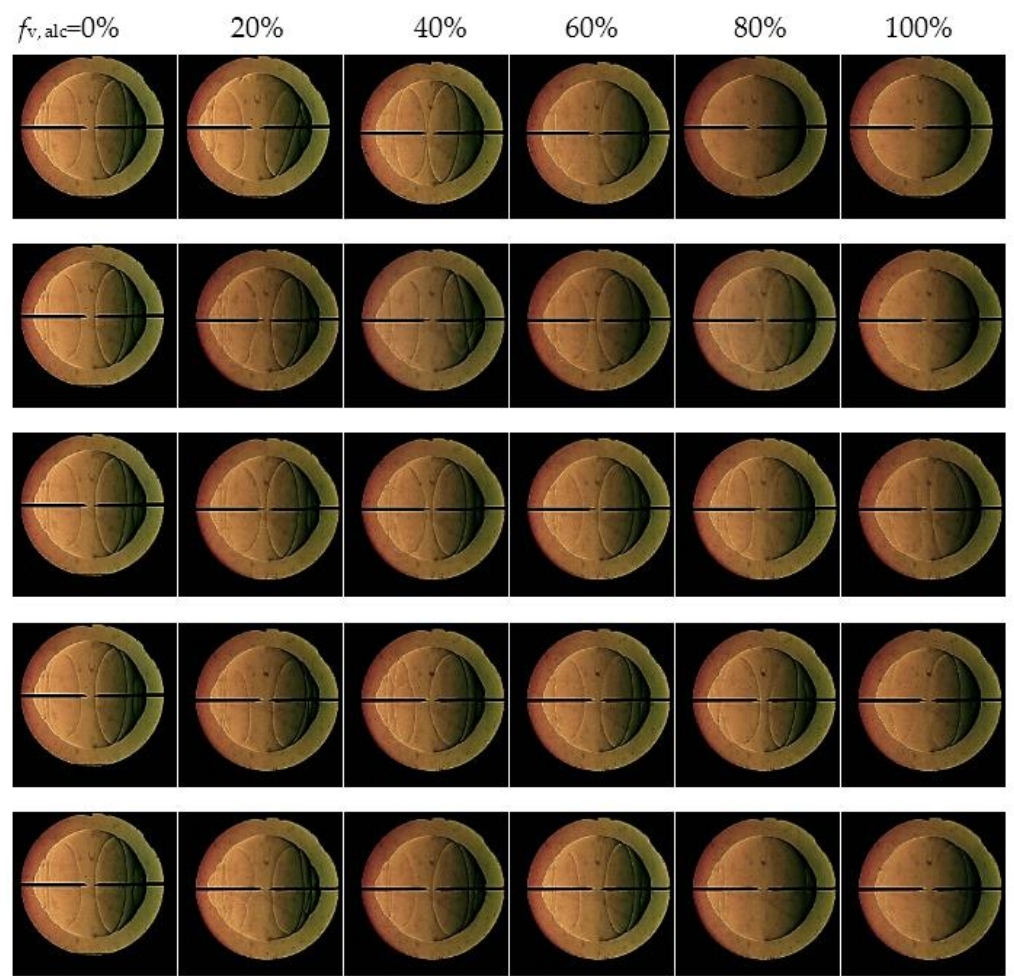

Methanol

+ isooctane

Ethanol

+ isooctane

$n$-Propanol

+ isooctane

n-Butanol

+ isooctane

$n$-Pentanol

+ isooctane

Figure 12. Schlieren images of C1-C5 primary alcohol-isooctane blends at $363 \mathrm{~K}, 0.1 \mathrm{MPa}$ and equivalence ratio of 1.5 .

\subsection{Laminar Flame Speed Correlation}

In fuel blending research, an equation giving accurate estimation on the laminar flame speeds of the blends is indispensable. As mentioned above, the laminar flame speeds of alcohol-isooctane blends exhibit nonlinear variation with the volume fraction of alcohol. An empirical correlation describing the dependence of laminar flame speed on the volume fraction of alcohol is given as:

$$
S_{\mathrm{u}, f_{v a}}^{0}=\frac{1}{\frac{1-f_{\mathrm{v}, \mathrm{alc}}}{S_{\mathrm{u}, \mathrm{C}_{8} \mathrm{H}_{18}}}+\frac{f_{\mathrm{v}, \mathrm{alc}}}{S_{\mathrm{u}, \mathrm{C}_{x} \mathrm{H}_{y} \mathrm{O}}}}
$$

where $f_{\mathrm{v}, \text { alc }}$ represents the blending ratio of alcohol in liquid volume, $S_{\mathrm{u}, \mathrm{C}_{8} \mathrm{H}_{18}}$ and $S_{\mathrm{u}, \mathrm{C}_{x} \mathrm{H}_{y} \mathrm{O}}$ indicate the laminar flame speeds of pure isooctane and alcohol flames under the same conditions (initial temperature, initial pressure and equivalence ratio), respectively. Such a correlation is derived based on the formula given by Di Sarli and Benedetto [60] with the mole fraction replaced by the volume fraction. The calculations with Equation (8) have been plotted in Figure 3. Good agreement is observed at different conditions for all alcohol-isooctane blends with deviations of less than $1.7 \mathrm{~cm} / \mathrm{s}$. 
Broustail et al. [29] proposed an empirical Equation to describe the laminar flame speed variation of the alcohol-isooctane blends with volume fraction of alcohol $\left(f_{\mathrm{v}, \text { alc }}\right)$, which is expressed as:

$$
S_{\mathrm{u}, f_{v a}}^{0}=S_{\mathrm{u}, \mathrm{C}_{8} \mathrm{H}_{18}}^{0}\left(\frac{S_{\mathrm{u}, \mathrm{C}_{x} \mathrm{H}_{y} \mathrm{O}}^{0}}{S_{\mathrm{u}, \mathrm{C}_{8} \mathrm{H}_{18}}^{0}} f_{\mathrm{v}, \text { alc }}\right.
$$

The calculations of Equations (8) and (9) were plotted in Figure 13 to allow comparisons with the experimental data at the equivalence ratios of 1.0 and 1.5. It is found that the two equations give similar estimations and satisfactory agreement with the experimental data for the blends of isooctane and C2-C5 primary alcohols. However, Equation (8) gives more accurate estimations than Equation (9) does for methanol-isooctane blends.
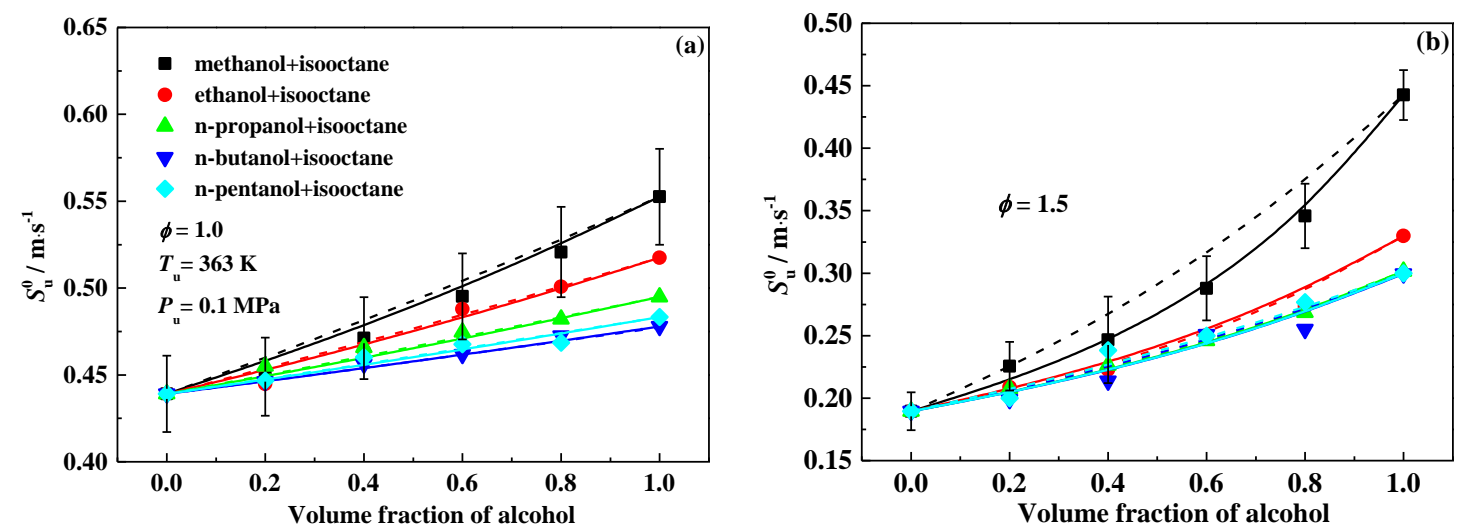

Figure 13. Experimental measurements and calculations at the equivalence ratios of 1.0 and 1.5 for C1-C5 primary alcohol-isooctane blends: (a) $\varphi=1.0$; and (b) $\varphi=1.5$. Symbols: experimental data; solid lines: calculations of Equation (8); dash lines: calculations of Equation (9).

More data of alcohols-isooctane blends in literatures [27-29,51] at various initial conditions were acquired to examine the feasibility of Equation (8). The measured laminar flame speeds [27-29,51] as well as the calculations of Equation (8) were plotted in Figure 14. The deviations between the measured data and the calculations are mainly within $\pm 2 \mathrm{~cm} / \mathrm{s}$, demonstrating good performance of the equation.

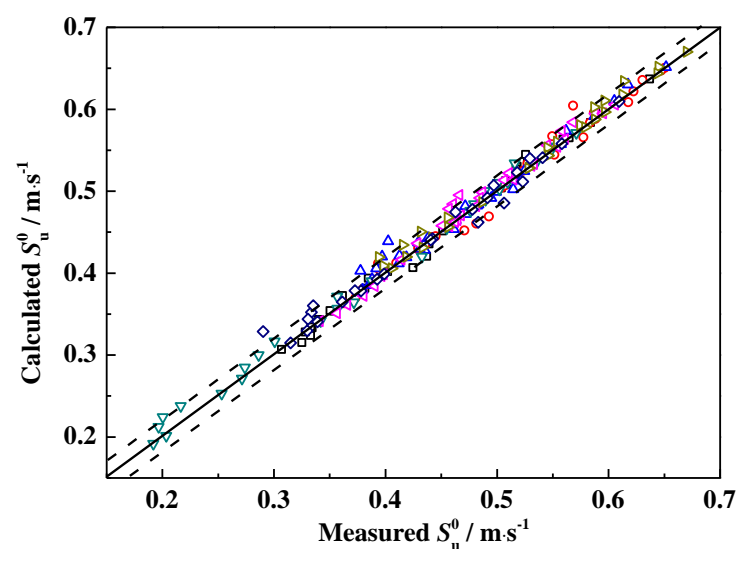

Figure 14. The measured laminar flame speeds in literatures $[27-29,51]$ vs. the calculated values with Equation (8) at various initial conditions. 


\section{Conclusions}

Laminar flame speeds of the blends of isooctane and C1-C5 primary alcohols were determined by the spherical propagating flame method at $363 \mathrm{~K}, 0.1 \mathrm{MPa}$, four equivalence ratios $(0.8,1.0,1.2$ and $1.5)$ and various blending ratios of alcohols $(0 \%-100 \%)$. The effects of blending different alcohols into isooctane on the laminar flame speed as well as the flame instability characteristics were comparatively illustrated. Finally, an empirical correlation was given based on the experimental data. The main conclusions are as follows:

(1) The laminar flame speeds of alcohol-isooctane blends increase monotonously with the addition of alcohol into isooctane. At a fixed alcohol blending ratio, methanol-isooctane blends present the highest values due to the chemical kinetic effect. Ethanol addition yields a comparable laminar flame speed enhancement as the additions of $n$-propanol, $n$-butanol and $n$-pentanol do at 0.8 and 1.5 , but stronger enhancement at 1.0 and 1.2.

(2) The laminar flame speeds of the alcohol-isooctane blends increase significantly with the increasing oxygen content in the blends. At the fixed oxygen content and equivalence ratio of 0.8 , the alcohol-isooctane blends exhibit similar values. At higher equivalence ratios, the addition of heavier alcohol tends to exhibit higher laminar flame speeds.

(3) Markstein length displays a decreasing tendency with the addition of alcohol into isooctane at the equivalence ratios of $0.8,1.0$ and 1.2 , however, it increases at 1.5. Therefore, the $L_{\mathrm{b}}-\varphi$ curve of the isooctane flame crosses with those of the pure $\mathrm{C} 1-\mathrm{C} 5$ primary alcohol flames. The equivalence ratios corresponding to the crosses are approximately 1.2-1.3.

(4) An empirical correlation was provided between the laminar flame speed and the volume fraction of alcohol based on the experimental data.

Supplementary Materials: The following are available online at www.mdpi.com/1996-1073/9/7/511/s1.

Acknowledgments: This work is supported by the National Natural Science Foundation of China (Grant No. 51406159, 91441203 and 50876085), the National Basic Research Program (2013CB228406), the China Postdoctoral Science Foundation (2014M560774), and State Key Laboratory of Engines, Tianjin University (K2016-02).

Author Contributions: The author contributions list is as follows: Study concepts were proposed by Qianqian Li and Zuohua Huang. Experimental studies, data processing, and the manuscript preparation were done by Qianqian Li. Data analysis and interpretation were done by Qianqian Li, Wu Jin and Zuohua Huang. Manuscript editing was made by Wu Jin. Manuscript revision were done by Wu Jin and Zuohua Huang.

Conflicts of Interest: The authors declare no conflict of interest.

\section{References}

1. Al-lwayzy, S.; Yusaf, T. Combustion of microalgae oil and ethanol blended with diesel fuel. Energies 2015, 8, 13985-13995. [CrossRef]

2. Gautam, M.; Martin, D.W. Combustion characteristics of higher-alcohol/gasoline blends. Proc. Inst. Mech. Eng. Part A J. Power Energy 2000, 214, 497-511. [CrossRef]

3. Gautam, M.; Martin, D.W.; Carder, D. Emissions characteristics of higher alcohol/gasoline blends. Proc. Inst. Mech. Eng. Part A J. Power Energy 2000, 214, 165-182. [CrossRef]

4. Karavalakis, G.; Durbin, T.D.; Shrivastava, M.; Zheng, Z.; Villela, M.; Jung, H. Impacts of ethanol fuel level on emissions of regulated and unregulated pollutants from a fleet of gasoline light-duty vehicles. Fuel 2012, 93, 549-558. [CrossRef]

5. Ozsezen, A.N.; Canakci, M. Performance and combustion characteristics of alcohol-gasoline blends at wide-open throttle. Energy 2011, 36, 2747-2752. [CrossRef]

6. Surisetty, V.R.; Dalai, A.K.; Kozinski, J. Alcohols as alternative fuels: An overview. Appl. Catal. A Gen. 2011, 404, 1-11. [CrossRef]

7. Szwaja, S.; Naber, J.D. Combustion of n-butanol in a spark-ignition IC engine. Fuel 2010, 89, $1573-1582$. [CrossRef] 
8. Yucesu, H.S.; Topgul, T.; Cinar, C.; Okur, M. Effect of ethanol-gasoline blends on engine performance and exhaust emissions in different compression ratios. Appl. Therm. Eng. 2006, 26, 2272-2278. [CrossRef]

9. Huang, Y.; Sung, C.J.; Eng, J.A. Laminar flame speeds of primary reference fuels and reformer gas mixtures. Combust. Flame 2004, 139, 239-251. [CrossRef]

10. Sileghem, L.; Alekseev, V.A.; Vancoillie, J.; Van Geem, K.M.; Nilsson, E.J.K.; Verhelst, S.; Konnov, A.A. Laminar burning velocity of gasoline and the gasoline surrogate components iso-octane, $n$-heptane and toluene. Fuel 2013, 112, 355-365. [CrossRef]

11. Foong, T.M.; Morganti, K.J.; Brear, M.J.; da Silva, G.; Yang, Y.; Dryer, F.L. The octane numbers of ethanol blended with gasoline and its surrogates. Fuel 2014, 115, 727-739. [CrossRef]

12. Bradley, D.; Hicks, R.A.; Lawes, M.; Sheppard, C.G.W.; Woolley, R. The measurement of laminar burning velocities and markstein numbers for iso-octane-air and iso-octane-n-heptane-air mixtures at elevated temperatures and pressures in an explosion bomb. Combust. Flame 1998, 115, 126-144. [CrossRef]

13. Davis, S.G.; Law, C.K. Laminar flame speeds and oxidation kinetics of iso-octane-air and $n$-heptane-air flames. Symp. Int. Combust. 1998, 27, 521-527. [CrossRef]

14. Ji, C.S.; Sarathy, S.M.; Veloo, P.S.; Westbrook, C.K.; Egolfopoulos, F.N. Effects of fuel branching on the propagation of octane isomers flames. Combust. Flame 2012, 159, 1426-1436. [CrossRef]

15. Kumar, K.; Freeh, J.E.; Sung, C.J.; Huang, Y. Laminar flame speeds of preheated iso-octane $/ \mathrm{O}_{2} / \mathrm{N}_{2}$ and n-heptane $/ \mathrm{O}_{2} / \mathrm{N}_{2}$ mixtures. J. Propuls. Power 2007, 23, 428-436. [CrossRef]

16. Li, Q.; Fu, J.; Wu, X.; Tang, C.; Huang, Z. Laminar flame speeds of DMF/iso-octane-air- $\mathrm{N}_{2} / \mathrm{CO}_{2}$ mixtures. Energy Fuels 2012, 26, 917-925. [CrossRef]

17. Metghalchi, M.; Keck, J.C. Burning velocities of mixtures of air with methanol, isooctane, and indolene at high-pressure and temperature. Combust. Flame 1982, 48, 191-210. [CrossRef]

18. Ryan, T.W.; Lestz, S.S. The laminar burning velocity of isooctane, n-heptane, methanol, methane, and propane at elevated temperature and pressures in the presence of a diluent. SAE Tech. Pap. 1980. [CrossRef]

19. Saeed, K.; Stone, C.R. Measurements of the laminar burning velocity for mixtures of methanol and air from a constant-volume vessel using a multizone model. Combust. Flame 2004, 139, 152-166. [CrossRef]

20. Zhang, Z.Y.; Huang, Z.H.; Wang, X.G.; Xiang, J.; Wang, X.B.; Miao, H.Y. Measurements of laminar burning velocities and markstein lengths for methanol-air-nitrogen mixtures at elevated pressures and temperatures. Combust. Flame 2008, 155, 358-368. [CrossRef]

21. Togbé, C.; Halter, F.; Foucher, F.; Mounaim-Rousselle, C.; Dagaut, P. Experimental and detailed kinetic modeling study of 1-pentanol oxidation in a JSR and combustion in a bomb. Proc. Combust. Inst. 2011, 33, 367-374. [CrossRef]

22. Veloo, P.S.; Wang, Y.L.; Egolfopoulos, F.N.; Westbrook, C.K. A comparative experimental and computational study of methanol, ethanol, and n-butanol flames. Combust. Flame 2010, 157, 1989-2004. [CrossRef]

23. Veloo, P.S.; Egolfopoulos, F.N. Studies of n-propanol, iso-propanol, and propane flames. Combust. Flame 2011, 158, 501-510. [CrossRef]

24. Beeckmann, J.; Cai, L.; Pitsch, H. Experimental investigation of the laminar burning velocities of methanol, ethanol, n-propanol, and n-butanol at high pressure. Fuel 2014, 117, 340-350. [CrossRef]

25. Sarathy, S.M.; Oßwald, P.; Hansen, N.; Kohse-Höinghaus, K. Alcohol combustion chemistry. Prog. Energy Combust. Sci. 2014, 44, 40-102. [CrossRef]

26. Zhang, X.; Tang, C.; Yu, H.; Huang, Z. Flame-front instabilities of outwardly expanding isooctane $/ n$-butanol blend-air flames at elevated pressures. Energy Fuels 2014, 28, 2258-2266. [CrossRef]

27. Zhang, X.; Tang, C.; Yu, H.; Li, Q.; Gong, J.; Huang, Z. Laminar flame characteristics of iso-octane/n-butanol blend-air mixtures at elevated temperatures. Energy Fuels 2013, 27, 2327-2335. [CrossRef]

28. Broustail, G.; Halter, F.; Seers, P.; Moréac, G.; Mounaïm-Rousselle, C. Experimental determination of laminar burning velocity for butanol/iso-octane and ethanol/iso-octane blends for different initial pressures. Fuel 2013, 106, 310-317. [CrossRef]

29. Broustail, G.; Seers, P.; Halter, F.; Moreac, G.; Mounaim-Rousselle, C. Experimental determination of laminar burning velocity for butanol and ethanol iso-octane blends. Fuel 2011, 90, 1-6. [CrossRef]

30. Gulder, Ö.L. Laminar burning velocities of methanol, isooctane and isooctane/methanol blends. Combust. Sci. Technol. 1983, 33, 179-192. [CrossRef]

31. Gülder, O.L. Burning velocities of ethanol isooctane blends. Combust. Flame 1984, 56, 261-268. [CrossRef] 
32. Song, H.; Quinton, K.; Peng, Z.; Zhao, H.; Ladommatos, N. Effects of oxygen content of fuels on combustion and emissions of diesel engines. Energies 2016, 9, 28. [CrossRef]

33. Sathiyagnanam, A.P.; Saravanan, C.G.; Gopalakrishnan, M. Hexanol-Ethanol Diesel Blends on DI-Diesel Engine to Study the Combustion and Emission. In Proceedings of the World Congress on Engineering (WCE 2010), London, UK, 30 June-2 July 2010; pp. 1-5.

34. Farkade, H.S.; Pathre, A.P. Experimental investigation of methanol, ethanol and butanol blends with gasoline on SI engine. Int. J. Emerg. Technol. Adv. Eng. 2012, 2, 2250-2459.

35. Tang, C.L.; Huang, Z.H.; Wang, J.H.; Zheng, J.J. Effects of hydrogen addition on cellular instabilities of the spherically expanding propane flames. Int. J. Hydrog. Energy 2009, 34, 2483-2487. [CrossRef]

36. Gu, X.L.; Huang, Z.H.; Wu, S.; Li, Q.Q. Laminar burning velocities and flame instabilities of butanol isomers-air mixtures. Combust. Flame 2010, 157, 2318-2325. [CrossRef]

37. Gu, X.; Li, Q.; Huang, Z.; Zhang, N. Measurement of laminar flame speeds and flame stability analysis of tert-butanol-air mixtures at elevated pressures. Energy Convers. Manag. 2011, 52, 3137-3146. [CrossRef]

38. Lapuerta, M.N.; García-Contreras, R.; Campos-Fernández, J.; Dorado, M.P. Stability, lubricity, viscosity, and cold-flow properties of alcohol-diesel blends. Energy Fuels 2010, 24, 4497-4502. [CrossRef]

39. Chen, Z. On the extraction of laminar flame speed and Markstein length from outwardly propagating spherical flames. Combust. Flame 2011, 158, 291-300. [CrossRef]

40. Frankel, M.L.; Sivashinsky, G.I. On effects due to thermal expansion and Lewis number in spherical flame propagation. Combust. Sci. Technol. 1983, 31, 131-138. [CrossRef]

41. Moffat, R.J. Describing the uncertainties in experimental results. Exp. Therm. Fluid Sci. 1988, 1, 3-17. [CrossRef]

42. Zhang, Y.; Shen, W.; Fan, M.; Zhang, H.; Li, S. Laminar flame speed studies of lean premixed $\mathrm{H}_{2} / \mathrm{CO} /$ air flames. Combust. Flame 2014, 161, 2492-2495. [CrossRef]

43. Krejci, M.C.; Mathieu, O.; Vissotski, A.J.; Ravi, S.; Sikes, T.G.; Petersen, E.L.; Kérmonès, A.; Metcalfe, W.; Curran, H.J. Laminar flame speed and ignition delay time data for the kinetic modeling of hydrogen and syngas fuel blends. J. Eng. Gas Turbines Power 2013, 135. [CrossRef]

44. Lowry, W.; de Vries, J.; Krejci, M.; Petersen, E.; Serinyel, Z.; Metcalfe, W.; Curran, H.; Bourque, G. Laminar flame speed measurements and modeling of pure alkanes and alkane blends at elevated pressures. J. Eng. Gas Turbines Power 2011, 133. [CrossRef]

45. Li, Q.; Tang, C.; Cheng, Y.; Guan, L.; Huang, Z. Laminar flame speeds and kinetic modeling of n-pentanol and its isomers. Energy Fuels 2015, 29, 5334-5348. [CrossRef]

46. Liao, S.Y.; Jiang, D.M.; Huang, Z.H.; Zeng, K.; Cheng, Q. Determination of the laminar burning velocities for mixtures of ethanol and air at elevated temperatures. Appl. Therm. Eng. 2007, 27, 374-380. [CrossRef]

47. Egolfopoulos, F.N.; Du, D.X.; Law, C.K. A study on ethanol oxidation kinetics in laminar premixed flames, flow reactors, and shock tubes. Symp. Int. Combust. 1992, 24, 833-841. [CrossRef]

48. Gülder, Ö.L. Laminar burning velocities of methanol, ethanol and isooctane-air mixtures. Symp. Int. Combust. 1982, 19, 275-281.

49. Baloo, M.; Dariani, B.M.; Akhlaghi, M.; Chitsaz, I. Effect of iso-octane/methane blend on laminar burning velocity and flame instability. Fuel 2015, 144, 264-273. [CrossRef]

50. Dirrenberger, P.; Glaude, P.A.; Bounaceur, R.; le Gall, H.; da Cruz, A.P.; Konnov, A.A.; Battin-Leclerc, F. Laminar burning velocity of gasolines with addition of ethanol. Fuel 2014, 115, 162-169. [CrossRef]

51. Rau, F.; Hartl, S.; Voss, S.; Still, M.; Hasse, C.; Trimis, D. Laminar burning velocity measurements using the heat flux method and numerical predictions of iso-octane/ethanol blends for different preheat temperatures. Fuel 2015, 140, 10-16. [CrossRef]

52. Wu, F.; Law, C.K. An experimental and mechanistic study on the laminar flame speed, Markstein length and flame chemistry of the butanol isomers. Combust. Flame 2013, 160, 2744-2756. [CrossRef]

53. Tang, C.L.; Huang, Z.H.; Law, C.K. Determination, correlation, and mechanistic interpretation of effects of hydrogen addition on laminar flame speeds of hydrocarbon-air mixtures. Proc. Combust. Inst. 2011, 33, 921-928. [CrossRef]

54. Law, C.K. Combustion Physics, 1st ed.; Cambridge University Press: Cambridge, UK, 2006.

55. Kee, R.J.; Grcar, J.F.; Smooke, M.D.; Miller, J.A. PRMIX: A Fortran Program for Modeling Steady Laminar One-Dimensional Premixed Flames; SAND Report 85-8240; Sandia National Laboratory: Livermore, CA, USA, 1985. 
56. Kee, R.J.; Dixon-Lewis, G.; Warnatz, J.; Coltrin, M.E.; Miller, J.A. A Fortran Computer Code Package for the Evaluation of Gas-Phase, Multicomponent Transport Properties; SAND-86-8246; Sandia National Laboratory: Livermore, CA, USA, 1986.

57. Kee, R.J.; Miller, J.A. Computational modeling of flame structure. Phys. D 1984, 12, 198-211. [CrossRef]

58. Kee, R.J.; Rupley, F.M.; Miller, J.A. Chemkin-II: A Fortran Chemical Kinetics Package for the Analysis of Gas-Phase Chemical Kinetics; Technical Report SAND89-8009; Sandia National Laboratory: Livermore, CA, USA, 1989.

59. Chaos, M.; Kazakov, A.; Zhao, Z.; Dryer, F.L. A high-temperature chemical kinetic model for primary reference fuels. Int. J. Chem. Kinet. 2007, 39, 399-414. [CrossRef]

60. Di Sarli, V.; Benedetto, A.D. Laminar burning velocity of hydrogen-methane/air premixed flames. Int. J. Hydrog. Energy 2007, 32, 637-646. [CrossRef]

(C) 2016 by the authors; licensee MDPI, Basel, Switzerland. This article is an open access article distributed under the terms and conditions of the Creative Commons Attribution (CC-BY) license (http://creativecommons.org/licenses/by/4.0/). 